\title{
Biorremediação de águas subterrâneas impactadas por gasolina e etanol com o uso de nitrato
}

\section{Nitrate bioremediation of groundwater impacted with gasoline and ethanol}

\author{
Ana Hilda Romero Costa \\ Bacharel em Química pela Universidade Federal do Ceará (UFCE). Doutora em Engenharia Ambiental pela Universidade Federal de Santa Catarina (UFSC)

\section{Cristina Cardoso Nunes} \\ Engenheira Química pela Universidade Estadual do Rio de Janeiro (UERJ). Doutora em Engenharia Ambiental pela UFSC

\section{Henry Xavier Corseuil} \\ Doutor em Engenharia Ambiental pela Universidade de Michigan. Professor-associado do Departamento de Engenharia Sanitária e Ambiental da UFSC
}

\begin{abstract}
Resumo
Neste estudo, avaliou-se, durante 32 meses e por meio de um experimento de campo, a utilização da biorremediação com injeção de nitrato na recuperação de águas subterrâneas impactadas por gasolina com 25\% de etanol. Por meio da análise da massa e da distribuição espacial dos compostos dissolvidos, verificou-se que a bioestimulação influenciou positivamente na biodegradação do etanol e dos BTEX, evitou a formação de zonas altamente redutoras (90\% dos valores foram superiores a $+100 \mathrm{mV}$ ) e impediu o avanço das plumas de BTEX e etanol na área monitorada. Os resultados indicam que a bioestimulação com nitrato é uma alternativa altamente eficiente para se remediarem águas subterrâneas impactadas por gasolina contendo etanol.
\end{abstract}

Palavras-chave: biorremediação; gasolina; etanol, nitrato, BTEX; águas subterrâneas.

\begin{abstract}
In this study, nitrate bioremediation in groundwater impacted with gasoline containing $25 \%$ ethanol was evaluated during 32 months in a field experiment. By means of mass and spatial distribution analysis of the dissolved compounds, biostimulation was found to have a positive influence on ethanol and BTEX biodegradation, and prevented the formation of highly reducing zones ( $90 \%$ of values were higher than $+100 \mathrm{mV}$ ) and BTEX and ethanol plume migration in the monitoring area. Results indicate that nitrate biostimulation is a highly efficient alternative in remediating groundwater impacted by gasohol.
\end{abstract}

Keywords: bioremediation; gasoline; ethanol; nitrate; BTEX; groundwater.

\section{Introdução}

Em casos de derramamento de combustíveis automotivos, como a gasolina em águas subterrâneas, os compostos monoaromáticos do grupo BTEX (benzeno, tolueno, etilbenzeno e xilenos) são os de maior interesse devido à sua toxicidade e mobilidade na subsuperfície. De acordo com a Resolução Conama 396/2008, o benzeno é considerado o mais tóxico dentre os BTEX, com padrão de potabilidade de $5 \mu \mathrm{g} \cdot \mathrm{L}^{-1}$. O tolueno, etilbenzeno e os xilenos são compostos regulados com concentração máxima permitida, em águas subterrâneas, de 170, 200 e $300 \mu \mathrm{g} . \mathrm{L}^{-1}$, respectivamente. O benzeno, dentre os compostos BTEX, é o mais solúvel em água (1780 mg.L-1), apresenta lenta degradação em condições anaeróbias (HUTCHINS, 1991; CUNNINGHAM et al, 2001), sendo o hidrocarboneto monoaromático que, geralmente, mais avança nas plumas dissolvidas de contaminação. No ambiente subsuperfícial contaminado por gasolina contendo etanol, o etanol, por sua alta solubilidade, estará presente na água subterrânea em concentrações muito superiores às dos BTEX. Dessa forma, o etanol e seus subprodutos de transformação, como o acetato e o metano, podem causar uma grande demanda de receptores de elétrons que poderiam ser utilizados na degradação dos compostos aromáticos mais tóxicos. No caso da presença simultânea de etanol e compostos BTEX em águas subterrânea, estudos demonstram que o etanol é o substrato preferencial dos micro-organismos tanto em condições aeróbias como anaeróbias (CORSEUIL; HUNT; SANTOS, 1998; ALVAREZ; HUNT, 2002). Os principais problemas da presença do etanol são: o aumento da concentração aquosa dos hidrocarbonetos na água 
subterrânea pelo efeito de co-solvência e a limitação da biodegradação dos compostos BTEX.

Diversas tecnologias têm sido utilizadas na remediação de solos e águas subterrâneas impactadas com hidrocarbonetos de petróleo. Quando os processos naturais de atenuação são limitados pela disponibilidade de nutrientes e receptores de elétrons, tecnologias de remediação ativas são utilizadas. Em função da baixa solubilidade do oxigênio, de seu rápido consumo pelos micro-organismos aeróbios e das dificuldades associadas à sua transferência para ambiente subsuperficial, a bioestimulação anaeróbia tem sido considerada uma alternativa atrativa na biorremediação de locais contaminados com hidrocarbonetos de petróleo (HUTCHINS; MILLER; THOMAS, 1998; SCHREIBER; BAHR, 2002). Dentre os receptores de elétrons que favorecem a biodegradação anaeróbia, o nitrato é termodinamicamente o mais favorável.

O nitrato pode ser utilizado por alguns micro-organismos através de duas diferentes rotas metabólicas: (1) como fonte de nutrientes (metabolismo assimilativo), que inclui a retirada de nutrientes do solo, transporte desses nutrientes para o interior da célula e subsequente utilização dos mesmos na biossíntese de macromoléculas; (2) como receptor de elétrons na produção de energia por meio da desnitrificação (metabolismo dissimilativo).

A injeção de receptores de elétrons anaeróbios (nitrato, sulfato etc.) pode diminuir a demanda causada pela degradação do etanol, evitando a formação de zonas altamente redutoras, as quais reduzem a taxa de degradação dos hidrocarbonetos de petróleo. Assim, a bioestimulação com nitrato possibilita a degradação do etanol em potenciais de oxi-redução ainda positivos, característicos de processos desnitrificantes, e permite que os receptores de elétrons naturais presentes na água subterrânea fiquem disponíveis para a biodegradação dos compostos BTEX. Experimentos em microcosmos com BTEX e etanol indicaram que o nitrato tem grande potencial para remover os impactos negativos do etanol na biorremediação dos BTEX Observou-se, ainda, que condições combinadas de receptores de elétrons (nitrato e ferro) favoreceram uma maior degradação do etanol e diminuição na produção de metano (SILVA; RUIZ-AGUILAR; ALVAREZ, 2005; CHEN; BARKER; GUI, 2008). No entanto, os resultados também evidenciaram que não somente o etanol, mas os subprodutos de sua degradação, como o acetato, levam vantagem sobre os BTEX na competição pelos receptores de elétrons disponíveis.

Neste estudo, dadas as especificidades da gasolina comercial brasileira e a necessidade da busca por tecnologias que minimizem os impactos ambientais causados pelos vazamentos de combustíveis, foram avaliadas as vantagens que a biorremediação com nitrato poderia trazer para a recuperação de águas subterrâneas impactadas com gasolina. Avaliaram-se também as limitações da injeção de nitrato considerando-se que a legislação ambiental estabelece o limite de 10 mg. L-1 $^{-1}$, equivalente a $45 \mathrm{mg} . \mathrm{L}^{-1} \mathrm{NO}_{3}^{-}$(CONAMA, 2008). O estudo apresentado foi realizado em campo, ou seja, permitiu uma avaliação da influência das condições dinâmicas nos processos de transporte e transformação dos contaminantes e subprodutos metabólicos em um ambiente natural.

\section{Material e métodos}

O experimento de biorremediação com nitrato em campo foi iniciado na área experimental da Fazenda da Ressacada (Florianópolis, SC) em 2004. A velocidade da água subterrânea na região do experimento é de aproximadamente $6 \mathrm{~m} / a n o$ e o nível médio do lençol varia entre 0,7 a 2,0 m. Os resultados das análises da água subterrânea coletadas antes do início do experimento nas profundidades de 2,3; 2,8; 3,8; 4,8 e 5,8 m estão apresentados na Tabela 1.

A direção do fluxo da água subterrânea na área experimental foi determinada a partir do monitoramento das flutuações dos níveis de poços piezométricos locados ao redor da área experimental e da construção de mapas potenciométricos, utilizando-se o modelo matemático bidimensional Solução Corretiva Baseada no Risco (SCBR) (CORSEUIL et al, 2006). O experimento ocupa uma área de $390 \mathrm{~m}^{2}$, com $30 \mathrm{~m}$ de comprimento e $13 \mathrm{~m}$ de largura, onde foram instalados, na direção do fluxo da água subterrânea, 50 poços de monitoramento multiníveis e seis poços para a injeção do receptor de elétrons e nutrientes. Os poços de monitoramento e injeção estão localizados a profundidades de 2,3; 2,8; 3,8; 4,8 e 5,8 m em relação à cota do terreno. A distribuição dos poços e a distância entre as linhas de poços de monitoramento em relação à fonte de contaminação $(X=743408$, 208; Y = 6935831, 067) são apresentadas na Figura 1.

Tabela 1 - Caracterização da água subterrânea antes da bioestimulação

\begin{tabular}{|c|c|c|c|}
\hline Parâmetros & Valores medidos & Parâmetros & Valores medidos \\
\hline Temperatura & $24^{\circ} \mathrm{C}$ & Sulfeto & $0 \mathrm{mg} \cdot \mathrm{L}^{-1}$ \\
\hline $\mathrm{pH}$ & 4,2 & Ferro (II) & $<0,1 \mathrm{mg} \cdot \mathrm{L}^{-1}$ \\
\hline $\begin{array}{l}\text { Potencial de } \\
\text { oxidação-redução }\end{array}$ & $+520 \mathrm{mV}$ & Fosfato & $<0,01 \mathrm{mg} \cdot \mathrm{L}^{-1}$ \\
\hline Oxigênio dissolvido & $3-5 \mathrm{mg} \cdot \mathrm{L}^{-1}$ & Metano & $<0,01 \mathrm{mg} \cdot \mathrm{L}^{-1}$ \\
\hline Nitrato & $1 \mathrm{mg} \cdot \mathrm{L}^{-1}$ & Acidez & $10 \mathrm{mgCaCO}_{3} \cdot \mathrm{L}^{-1}$ \\
\hline Sulfato & $4 \mathrm{mg} \cdot \mathrm{L}^{-1}$ & Condutividade & $50 \mu$ S. $\mathrm{cm}^{-1}$ \\
\hline
\end{tabular}


Em dezembro de 2004, foram liberados, no nível do lençol freático, $100 \mathrm{~L}$ de gasolina contendo $25 \%$ de etanol em área de $1 \mathrm{~m}^{2} \mathrm{e}$ profundidade de $1 \mathrm{~m}$ da superfície. Na fonte, inicialmente, a massa de benzeno era aproximadamente de 0,3 kg e a de etanol de 19,8 $\mathrm{kg}$. O íon brometo foi utilizado como traçador devido ao seu caráter conservativo. A injeção de nitrato ocorreu de fevereiro a novembro de 2005, três vezes por semana. A solução injetada foi preparada com nitrato de sódio $\left(\mathrm{NaNO}_{3}\right)$ e fosfato de potássio monobásico $\left(\mathrm{KH}_{2} \mathrm{PO}_{4}\right)$. Em projetos de remediação, quantidades significativas de dois nutrientes, nitrogênio $(\mathrm{N})$ e fósforo $(\mathrm{P})$, são necessárias para o metabolismo de biodegradação pelos micro-organismos. A solução era saturada com gás nitrogênio para retirada de oxigênio. A injeção diária de $5 \mathrm{~L}$ por poço foi realizada por meio de bombas peristálticas multiníveis simultaneamente nos cinco níveis de cada poço. A concentração da solução de nitrato injetada, nesse período, variou entre 4 e $29 \mathrm{~g} \cdot \mathrm{L}^{-1}$. A quantidade de nutriente adicionado seguiu a relação de C:N:P (em mols) de 100:10:1 (KWOK; LOH, 2003)

Durante a bioestimulação, foram utilizados $38,7 \mathrm{~kg}$ de nitrato, sendo que a maior massa foi injetada nas profundidades 2,3 e 2,8 m $(9,7 \mathrm{~kg}$ em cada profundidade). No nível 3,8 m, foram injetados $7,9 \mathrm{~kg}$ de nitrato e nos demais níveis (4,8 e 5,8 m), foram injetados $5,7 \mathrm{~kg}$ de nitrato por profundidade. A quantidade de nitrato injetada em cada profundidade foi definida com base na massa de BTEX e de etanol presentes na fonte de contaminação, na relação estequiométrica entre esses compostos e o receptor de elétrons, e na avaliação do fluxo de massa na região da fonte de contaminação.

De dezembro de 2004 a setembro de 2007, foram realizadas coletas $1,4,6,10,13,17,21,25$ e 32 meses após o início do experimento. As amostras foram analisadas em um cromatógrafo a gás da HP (modelo 6890, série II) com Headspace Auto Sampler HP estático (modelo 7694) equipado com detector por ionização em chama (FID), conectado a um computador com o Software ChemStation Plus. O gás de arraste empregado foi o hélio, com velocidade de $2,0 \mathrm{ml} / \mathrm{min}^{-1} \mathrm{em}$ todas as análises. Utilizou-se coluna capilar de sílica fundida: HP 1 (metil siloxano) no 19095z-123 (HP, USA) com 0,53 mm de diâmetro interno, com 30 $\mathrm{m}$ de comprimento e espessura do filme de 2,65 $\mu \mathrm{m}$. As temperaturas do injetor e detector foram mantidas, respectivamente, a $260^{\circ} \mathrm{C}$ e 280 ${ }^{\circ} \mathrm{C}$, para os BTEX e o etanol, e a $190^{\circ} \mathrm{C}$ e $250^{\circ} \mathrm{C}$, para o metano. Para os BTEX e etanol foi usada temperatura programada de $70^{\circ} \mathrm{C}$ a $120^{\circ} \mathrm{C}$ a $5^{\circ} \mathrm{C} /$ min e $120^{\circ} \mathrm{C}$ a $210^{\circ} \mathrm{C}$ a $30^{\circ} \mathrm{C} / \mathrm{min}$. Para o metano, a temperatura foi programada de $40^{\circ} \mathrm{C}$ a $250^{\circ} \mathrm{C}$ a $30^{\circ} \mathrm{C} / \mathrm{min}$. Os padrões utilizados foram: UST Modified Gasoline Range Organics da Supelco para os BTEX e o etanol da indústria MERCK, com 99,9\% de pureza. Para o metano, a solução-padrão foi preparada a partir de uma mistura-padrão de 65\% de metano e $25 \%$ de dióxido de carbono. Para a análise em cromatógrafo gasoso, utilizou-se uma alíquota de $10 \mathrm{~mL}$ da amostra, acondicionada em um vial e submetida à extração por headspace.

Os compostos nitrato, nitrito e brometo foram analisados por meio de cromatografia líquida, em cromatógrafo iônico (Dionex,

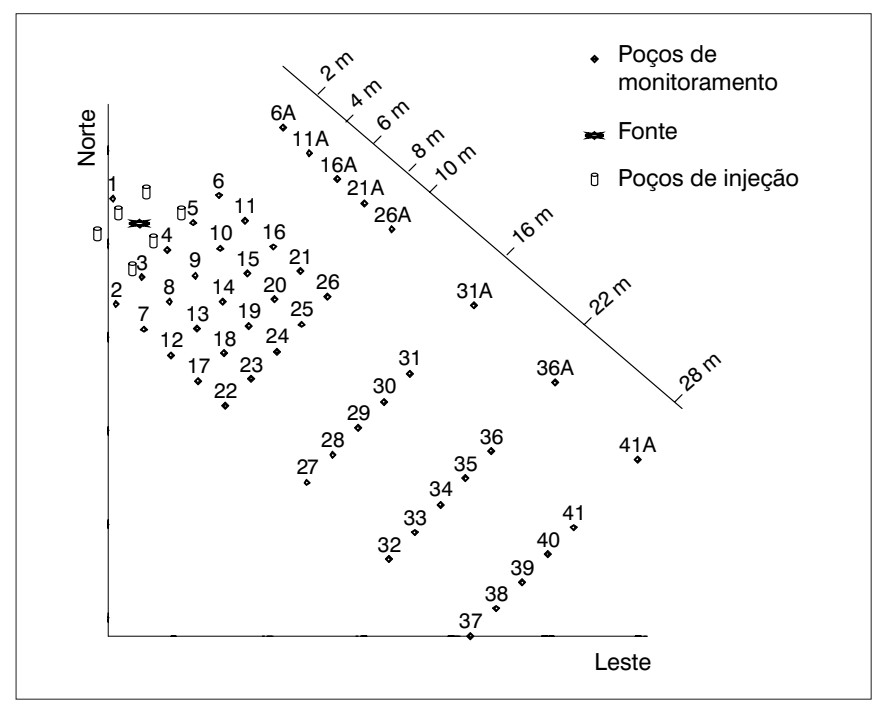

Figura 1 - Distribuição dos poços de monitoramento e de injeção e distância entre as linhas de poços de monitoramento relativamente à fonte de contaminação na área experimental II

modelo ICS-1000), equipado com detector de condutividade iônica, conectado a um computador com o Software Chromeleon PN 6.40. A coluna utilizada foi a AS4A-SC. Como fases móveis, foram utilizadas as soluções de carbonato e bicarbonato de sódio com vazão de 1 $\mathrm{mL} / \mathrm{min}$. Os padrões utilizados foram todos da marca J.T.BAKER e o método empregado foi o chromatography with chemical suppression of eluent condutivity, do Standard Methods (APHA/AWWA/WEF, 1992). $\mathrm{Na}$ análise por cromatografia de íons, foram utilizados $5 \mathrm{~mL}$ da amostra, injetada utilizando-se amostrador automático.

O limite de detecção do CG utilizado nas condições de análise para os compostos BTEX, o etanol e o metano foi, respectivamente, $1 \mu \mathrm{g} . \mathrm{L}^{-1}$, $1 \mathrm{mg} . \mathrm{L}^{-1}$ e $1 \mu \mathrm{g}$. $\mathrm{L}^{-1}$. A precisão dos dados obtidos no CG foi testada de acordo com a porcentagem de recuperação do 'fortificado', segundo normas descritas pela EPA/8015A. A porcentagem de recuperação para os compostos BTEX variou entre 118,8 e $86 \%$ e para o etanol, entre 107,1 e 95,8\%. A porcentagem de exatidão da análise para os compostos BTEX variou entre 131 e 81\%; para o etanol, entre 117 e $83 \%$.

O monitoramento de áreas impactadas, necessário para a avaliação dos riscos potenciais de contaminação, inclui tanto a quantificação de massa como a distribuição espacial dos contaminantes e subprodutos metabólicos envolvidos nos processos de biodegradação. Interpoladores espaciais (determinísticos e estocásticos) vêm sendo utilizados com essas finalidades, tanto para a estimativa de massa (COOPER; STOK, 1988), como para a análise da distribuição espacial de contaminantes (CATTLE; McBRATNEY; MINASNY, 2002; ALMEIDA et al, 2007). Para o tratamento dos dados de campo, utilizou-se a interpolação espacial krigagem indicativa. A krigagem indicativa é uma técnica de estimação aplicada sobre os valores transformados do atributo segundo um mapeamento não-linear denominado codificação por indicação. A transformação indicadora da função aleatória Z, utilizada neste trabalho, para um valor de corte fixo $\mathrm{v}_{\mathrm{c}}$ é definida por: 
$I(x ; v c)=\left\{\begin{array}{l}1 \text { se } z(x) \geq v_{c} \\ 0 \text { se } z(x)<v_{c}\end{array}\right.$

Equação 1

onde:

$z(\mathrm{x})$ : valor observado.

Optou-se por considerar os valores superiores ao valor de corte (valores orientadores em casos de contaminação) como 1 e os inferiores, como zero. O semivariograma dos valores transformados é estimado pela Equação 2:

$\gamma_{\mathrm{I}}\left(\mathrm{h}, \mathrm{v}_{\mathrm{c}}\right)=\frac{1}{2 \mathrm{~N}_{\mathrm{h}}} \sum_{\mathrm{i}=1}^{\mathrm{N}(\mathrm{h})}\left[\mathrm{I}\left(\mathrm{x}_{1} ; \mathrm{v}_{\mathrm{c}}\right)-\mathrm{I}\left(\mathrm{x}_{\mathrm{i}}+\mathrm{h}, \mathrm{v}_{\mathrm{c}}\right)\right]^{2}$

Equação 2

onde:

h: passo (lag) básico entre os locais x e x+h;

$\mathrm{v}_{\mathrm{c}}$ : valor de corte;

$\mathrm{N}$ : número de pares para $\mathrm{x}$ e $\mathrm{x}+\mathrm{h}$.

O resultado final são mapas de distribuição espacial dos contaminantes que apontam a probabilidade ( 0 a 1 ) de sua concentração ser superior ao nível de corte escolhido na área monitorada (LANDIM, 2003).

Na elaboração dos mapas de distribuição espaciais, os valores de corte (VC) escolhidos foram baseados nos padrões de potabilidade estabelecidos (CONAMA, 2008) para os compostos BTEX, benzeno e o nitrato. O VC considerado para o benzeno foi de $5 \mu \mathrm{g} . \mathrm{L}^{-1}$, enquanto para o nitrato, o VC foi de $45 \mathrm{mg} \cdot \mathrm{L}^{-1} \mathrm{NO}_{3}^{-}\left(10 \mathrm{mg} \cdot \mathrm{L}^{-1} \mathrm{~N}\right)$. O nível de corte escolhido para os compostos BTEX foi de $100 \mu \mathrm{g} \cdot \mathrm{L}^{-1}$. Para o brometo, o VC foi definido de acordo com o valor da mediana (0,05 mg. $\left.\mathrm{L}^{-1}\right)$ e teve como objetivo o acompanhamento do transporte conservativo na água subterrânea. Para o etanol, o VC escolhido foi de $10 \mathrm{mg} \cdot \mathrm{L}^{-1}$, que representaria o esgotamento do etanol no meio monitorado. Para o oxigênio dissolvido, foi considerado o VC de 3 mg. $\mathrm{L}^{-1}$ como o limite entre a zona aeróbia e anaeróbia (SCHREIBER; BAHR, 2002). Neste trabalho, considerou-se que, quanto mais próximo de 1 , maior a probabilidade da concentração observada no meio estar acima do VC definido para as variáveis analisadas, e quanto mais próximo de zero, menor a probabilidade de ocorrência de valores superiores ao valor de corte. Além disso, a probabilidade 0,5 (50\%) foi destacada com uma linha branca tracejada em todos os mapas, significando que, no interior dessa área, a probabilidade de ocorrência dos eventos é superior a 50\%. Na confecção dos mapas probabilísticos, foram utilizados os programas GEOEAS, Variowin 2.2 e Surfer 8.0 (LANDIM; USHIZIMA, 2003).

A estimativa da massa dissolvida dos doadores de elétrons (BTEX e etanol) e do receptor de elétrons $\left(\mathrm{NO}_{3}^{-}\right)$foi realizada por meio de interpoladores espaciais de acordo com a metodologia apresentada por Cooper e Istok (1988), adaptada para o método da mínima curvatura
(NUNES; CORSEUIL, 2007). Para esse cálculo, foi considerada a porosidade efetiva $(\eta \varepsilon)$ igual a 0,20 e a espessura das plumas de $0,75 \mathrm{~m}$ para os níveis 2,3 e 2,8 m, e 1 m para os níveis 3,8 a 5,8 m.

\section{Resultados e discussão}

\section{Avaliação da massa dissolvida}

A redução de massa dos compostos BTEX pode ocorrer por processos microbianos, biodegradação, e por processos abióticos, como volatilização. Chiang et al (1989) demonstraram que menos de 5\% da massa de BTEX dissolvida é perdida para a fase gasosa do solo na zona saturada. Por causa disso, o impacto da volatilização na redução do contaminante dissolvido pode ser geralmente desprezado (WIEDEMEIER et al, 1999). Neste trabalho, a perda de massa por volatilização não foi considerada.

As massas de BTEX e etanol, ao longo do tempo, são influenciadas pela taxa de transferência de massa da fonte para a água subterrânea e pela taxa de biodegradação desses compostos. Como o etanol é o substrato preferencial, a biodegradação dos BTEX irá ocorrer somente após a degradação do etanol (CORSEUIL; HUNT; SANTOS, 1998; NUNES; CORSEUIL, 2007). A Figura 2 apresenta a variação da massa dissolvida de etanol e de BTEX na área experimental. Durante o período de bioestimulação com nitrato não houve biodegradação dos BTEX devido à grande quantidade de etanol dissolvido biodisponível para ser degradado. A massa dissolvida de etanol quantificada diminuiu de $15 \mathrm{~kg}$ para $1 \mathrm{~kg}$, entre 5 e 32 meses, o que representou uma redução de 94\% da quantidade máxima de etanol. A maior massa dissolvida estimada de BTEX foi obtida aos 17 meses (280 g). Aos 32 meses de monitoramento, com a diminuição significativa da massa de etanol, a massa de BTEX foi reduzida em mais de $40 \%$ (161 g).

A evidência da degradação de etanol em condições desnitrificantes pode ser demonstrada pelo balanço de massa da relação entre nitrato consumido e etanol biodegradado (Figura 3). Durante os 32 meses de monitoramento, foram degradados $18,7 \mathrm{~kg}$ de etanol, ficando remanescente na área apenas $1,1 \mathrm{~kg}$. No mesmo período, dos 38,7 $\mathrm{kg}$ de nitrato injetados, 28,7 kg foram consumidos, 7,8 $\mathrm{kg}$ estavam ainda presentes na área e 2,2 kg de nitrato haviam saída da área experimental. Essa massa de nitrato não utilizada ( $6 \%$ da massa total injetada), que saiu do meio monitorado, foi calculada por meio do fluxo de massa (AMERICAN PETROLEUM INSTITUTE, 2003) para a última linha de poços de monitoramento. Dessa forma, a relação entre a quantidade de nitrato consumido e etanol degradado medida experimentalmente foi de $1,53 \mathrm{~kg}$ de $\mathrm{NO}_{3}-1 \mathrm{~kg}$ de $\mathrm{EtOH}$.

A relação nitrato/etanol obtida experimentalmente pode ser comparada com a relação estequiométrica de equilíbrio com crescimento celular obtida através do modelo bioenergético de Rittmann e McCarty (2001). Essa relação é dada pela Equação 3 (COSTA, 2008): 


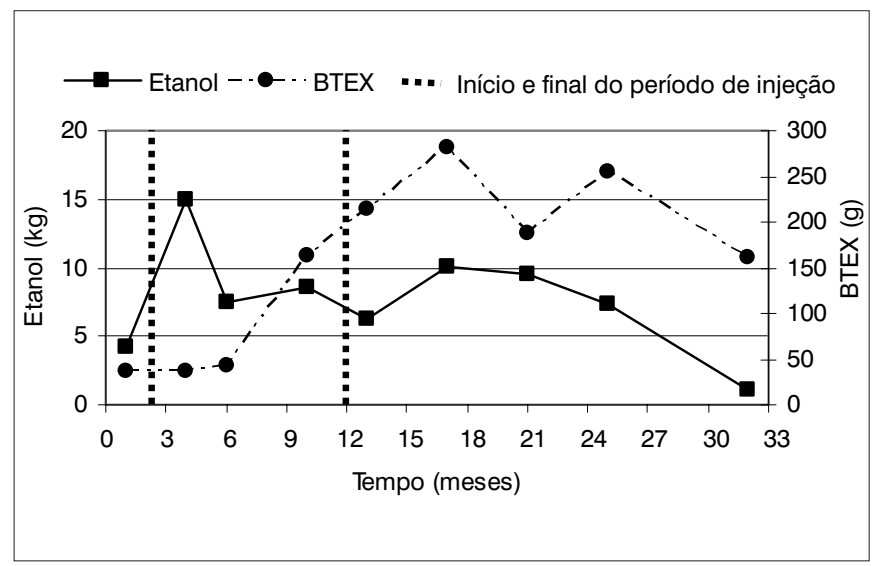

Figura 2 - Variação da massa dissolvida dos BTEX e etanol com a bioestimulação com nitrato

$\mathrm{C}_{2} \mathrm{H}_{6} \mathrm{O}+1,06 \mathrm{NO}_{3}^{-}+1,06 \mathrm{H}^{+} \rightarrow 0,289 \mathrm{C}_{5} \mathrm{H}_{7} \mathrm{O}_{2} \mathrm{~N}$

$+0,554 \mathrm{CO}_{2}+0,385 \mathrm{~N}_{2}+2,518 \mathrm{H}_{2} \mathrm{O}$

Equação 3

Nesta equação, para cada mol de etanol degradado, são consu-

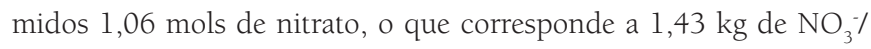
$\mathrm{kg}$ de $\mathrm{EtOH}$. Esse valor difere em menos de $10 \%$ da relação obtida experimentalmente $\left(1,53 \mathrm{~kg}\right.$ de $\mathrm{NO}_{3}^{-} / \mathrm{kg}$ de $\left.\mathrm{EtOH}\right)$. Dessa forma, os resultados indicam que a redução da massa de etanol está diretamente associada ao consumo de nitrato, o que evidencia a ocorrência do processo de desnitrificação como principal responsável pela degradação no etanol na área experimental. Quanto ao nitrito, 90\% dos poços e níveis monitorados apresentaram concentração de nitrito menor que $1 \mathrm{mg} \cdot \mathrm{L}^{-1}$.

\section{Avaliação da distribuição espacial por profundidade}

A análise da distribuição espacial dos compostos químicos envolvidos na bioestimulação com nitrato permite a avaliação do comportamento do avanço das plumas de contaminação, sua relação entre o processo de injeção de nitrato e a dissolução dos contaminantes da fonte, bem como a inter-relação entre consumo de nitrato e biodegradação de etanol e compostos BTEX. Para esta análise, foram utilizadas as campanhas de monitoramento de 10, 17, 25 e 32 meses após o início do experimento e as profundidades de 2,3 e 5,8 m. As massas de nitrato injetados nos níveis 2,3 e 5,8 m foram de 9,7 e 5,7 $\mathrm{kg}$, respectivamente. A escolha desses dois níveis permite avaliar o comportamento do avanço das plumas em função da quantidade de nitrato injetada e também a influência de uma menor disponibilidade de oxigênio no nível mais profundo.

A análise da distribuição espacial das plumas é apresentada para o traçador brometo, compostos BTEX totais, etanol, benzeno, oxigênio e nitrato (Figura 4 e 5). Os mapas de distribuição espacial destacam a probabilidade (entre 0 e 1 ) do respectivo composto estar em concentrações superiores ao nível de corte escolhido. O destaque

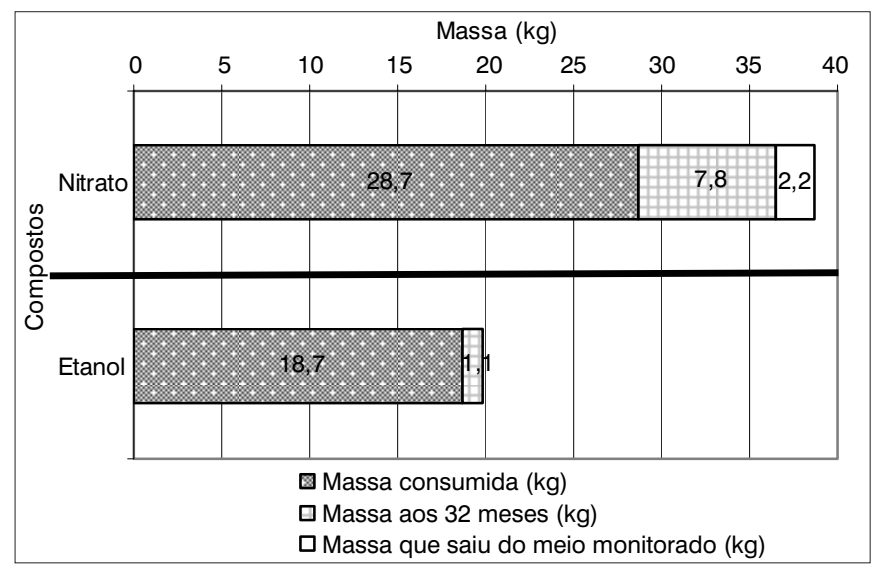

Figura 3 - Balanço de massa do nitrato e do etanol após 32 meses de monitoramento

nos mapas é dado para as concentrações superiores ao nível de corte escolhido. Em todos os mapas, as áreas com probabilidade igual ou superior a $50 \%$ nas quais os valores de corte tenham sido superados são enfatizadas por uma linha tracejada branca. O comprimento das plumas é definido pelas áreas com probabilidade igual ou superior a $50 \%$ nas quais as concentrações em questão superam o nível de corte escolhido. Como o brometo é um composto conservativo, pode-se observar o seu espalhamento e sua saída do meio monitorado a partir dos 17 meses para as duas profundidades analisadas. Por outro lado, as plumas de etanol e BTEX que inicialmente avançam no meio monitorado, recuam para a região próxima à fonte devido ao processo de biodegradação.

Na profundidade 2,3 m (Figura 4), a pluma de BTEX (VC = 100 $\left.\mu \mathrm{g} . \mathrm{L}^{-1}\right)$ praticamente não avançou até os 32 meses de monitoramento. As plumas de etanol $\left(\mathrm{VC}=10 \mathrm{mg} \cdot \mathrm{L}^{-1}\right)$ e benzeno $\left(\mathrm{VC}=5 \mu \mathrm{g} \cdot \mathrm{L}^{-1}\right)$ atingiram o comprimento máximo aos 17 e 25 meses, respectivamente. Aos 32 meses de monitoramento, a pluma de benzeno retrocedeu para próximo da fonte (4 m) e o etanol foi completamente degradado. A exaustão do oxigênio ( $\left.\mathrm{VC}=3 \mathrm{mg} \cdot \mathrm{L}^{-1}\right)$, ocasionada pela degradação do etanol, pode ser observada na Figura 4, aos 17 meses, onde a área clara indica que as concentrações de OD (Oxigênio Dissolvido) são inferiores a $3 \mathrm{mg} \cdot \mathrm{L}^{-1}$. No entanto, nos outros monitoramentos, o OD no nível 2,3 m está acima de $3 \mathrm{mg} \cdot \mathrm{L}^{-1} \mathrm{em}$ praticamente toda a área experimental. A recuperação da concentração de oxigênio nesse nível está associada à proximidade da zona não-saturada e a degradação do etanol em condições desnitrificantes. Quanto ao nitrato, o seu consumo na fonte foi constatado durante todos os períodos monitorados, já que a sua concentração na fonte foi sempre inferior a $45 \mathrm{mg} \cdot \mathrm{L}^{-1}$ $\mathrm{NO}_{3}$. O pequeno avanço da pluma dos compostos BTEX no nível 2,3 m pode ser explicado pela presença concomitante de oxigênio e nitrato no ambiente, já que os BTEX podem ser biodegradados tanto em condições aeróbicas como em condições desnitrificantes (principalmente os TEX) (WILSON; D'ADAMO, BOWER, 1997).

$\mathrm{Na}$ profundidade de 5,8 m, o comportamento das plumas de BTEX, etanol e nitrato foi completamente diferente do observado na 
profundidade 2,3 m (Figura 5). Na região mais profunda, houve um avanço contínuo das plumas de BTEX e etanol até $22 \mathrm{~m}$ da região da fonte e uma menor concentração de OD e nitrato em toda a área monitorada. As explicações para essas diferenças estão associadas à injeção de uma massa de nitrato 40\% inferior à injetada no nível 2,3 m e a menor difusão de oxigênio que ocorre no nível mais afastado da zona não-saturada. A presença concomitante dos compostos BTEX e etanol nas regiões, nas quais oxigênio e nitrato estão ausentes, demonstra o efeito negativo do etanol de impedir a degradação dos BTEX.

A presença da pluma de etanol aos 32 meses de monitoramento pode ser atribuída à menor injeção de nitrato aplicada no nível 5,8 m e a ausência de condições redutoras mais negativas que permitissem a degradação do etanol com outros receptores de elétrons anaeróbicos. Nesse nível, observa-se ainda o fenômeno de separação das plumas de BTEX que pode ocorrer quando a pluma de etanol se afasta da região da fonte de contaminação. Um resumo do avanço e retardo das plumas de benzeno, etanol e compostos BTEX para os níveis 2,3 m e 5,8 m é apresentado na Figura 6, onde se observa o efeito positivo da bioestimulação com nitrato principalmente no nível 2,3 m. Para a determinação do comprimento das plumas, não foi considerada a sua separação.

O conceito de sequência de potenciais de oxidação-redução auxilia a delimitação de zonas de oxidação-redução nas águas subterrâneas. Edmund, Miles e Cook (1984) propuseram uma sequência de quatro intervalos: (1) oxigênio-nitrogênio, (2) ferro, (3) sulfato e (4) metanogênese. Os potenciais correspondentes a esses intervalos eram respectivamente: (+) $250 \mathrm{mV}$ a (+) $100 \mathrm{mV},(+) 100 \mathrm{mV}$ a zero mV, zero a (-) $200 \mathrm{mV}$ e abaixo de (-) 200 mV. A análise dos dados de campo do experimento de biorremediação (1474 amostras) revelou que a mediana do potencial de oxidação-redução para todos os níveis monitorados durante 32 meses foi sempre superior a +230 mV. Além disso, 90\% dos valores observados (1.376 amostras) nesse período tiveram potenciais de oxidação superiores a $+100 \mathrm{mV}$. A partir dos valores de potenciais positivos durante todo monitoramento e da análise comparativa com resultado obtido por Edmund, Miles e Cook (1984), pôde-se concluir que os processos dominantes ocorreram em condições aeróbias e desnitrificantes. Além dos valores de potenciais de oxidação-redução, a variação do pH e da concentração de OD podem ser considerados como indicativo da ocorrência da desnitrificação. No experimento da bioestimulação, o pH inicial foi de 4,2 e a variação nos dois níveis (2,3 e 5,8 m) situou-se entre 4,12 e 4,56, não sendo possível verificar uma tendência na variação do $\mathrm{pH}$.

A análise da distribuição espacial do nitrato na área experimental é importante tanto para a avaliação da eficiência do processo de desnitrificação, como para avaliação de sua saída do meio monitorado, já que o nitrato é um composto com limite máximo estipulado pela Portaria Federal MS 518/2004. A injeção de uma massa maior de nitrato no nível 2,3 m possibilitou a degradação total do etanol e um menor avanço nas plumas de BTEX. No entanto, uma parcela do nitrato injetado não foi utilizada na degradação dos compostos orgânicos presentes e avançou para fora dos limites da área monitorada. Para se avaliarem as concentrações de nitrato que saíram da área experimental, foi realizada uma análise comparativa das concentrações medianas, mínimas e máximas nas duas últimas campanhas de monitoramento, na seção transversal formada pela última fileira de poços de monitoramento multiníveis do experimento de bioestimulação (Figura 7). Essa seção está localizada $28 \mathrm{~m}$ à jusante da fonte de contaminação e é formada pelos poços multiníveis P37 a P41 (Figura 1). Aos 25 e 32 meses após o início do experimento, observou-se a saída de nitrato com concentrações pontuais superiores ao padrão de potabilidade ( $45 \mathrm{mg} \cdot \mathrm{L}^{-1} \mathrm{NO}_{3}^{-}$), conforme foi observado nas Figuras 4 e 5, pelas regiões destacadas por uma linha tracejada branca próxima ao extremo da área monitorada. No entanto, a mediana, calculada com base na concentração em 25 pontos, nunca superou o padrão de potabilidade e, aos 32 meses, $75 \%$ dos pontos amostrados atendiam às exigências ambientais. Esses resultados mostram que as concentrações de nitrato em excesso na área diminuíram continuamente ao longo do tempo, não caracterizando risco a receptores localizados à jusante da área experimental.

\section{Conclusões}

A bioestimulação com nitrato influenciou positivamente a biodegradação do etanol e dos compostos BTEX na área experimental. A redução de mais de $90 \%$ da massa de etanol da área monitorada foi atribuída ao processo de desnitrificação, uma vez que mais de $27 \mathrm{~kg}$ de nitrato foram consumidos durante os 32 meses de monitoramento. Dessa forma, a adição de nitrato atendeu à grande demanda de receptores de elétrons ocasionada pela degradação do etanol, e evitou a formação de zonas altamente redutoras que dificultam a degradação dos BTEX. A rápida recuperação das condições aeróbicas ocorridas após a degradação do etanol no nível 2,3 $\mathrm{m}$, onde nitrato foi adicionado em maior quantidade, possibilitou a degradação dos BTEX, cuja pluma ficou restrita à região onde estava presente a fase pura de gasolina. No nível mais profundo, onde se injetou uma menor massa de nitrato, o etanol não foi completamente degradado. A presença de etanol nessa profundidade impediu a degradação dos compostos monoaromáticos e possibilitou o avanço das plumas de BTEX.

Este estudo indica que o foco principal de uma remediação de águas subterrâneas impactadas com gasolina e etanol deve ser a rápida degradação do etanol. A eficácia da degradação do etanol em condições desnitrificantes indica que a bioestimulação com injeção de nitrato é uma alternativa viável na remediação de áreas impactadas com gasolina e etanol. Ante a preocupação associada à injeção do nitrato em sistemas de biorremediação, o monitoramento das últimas 


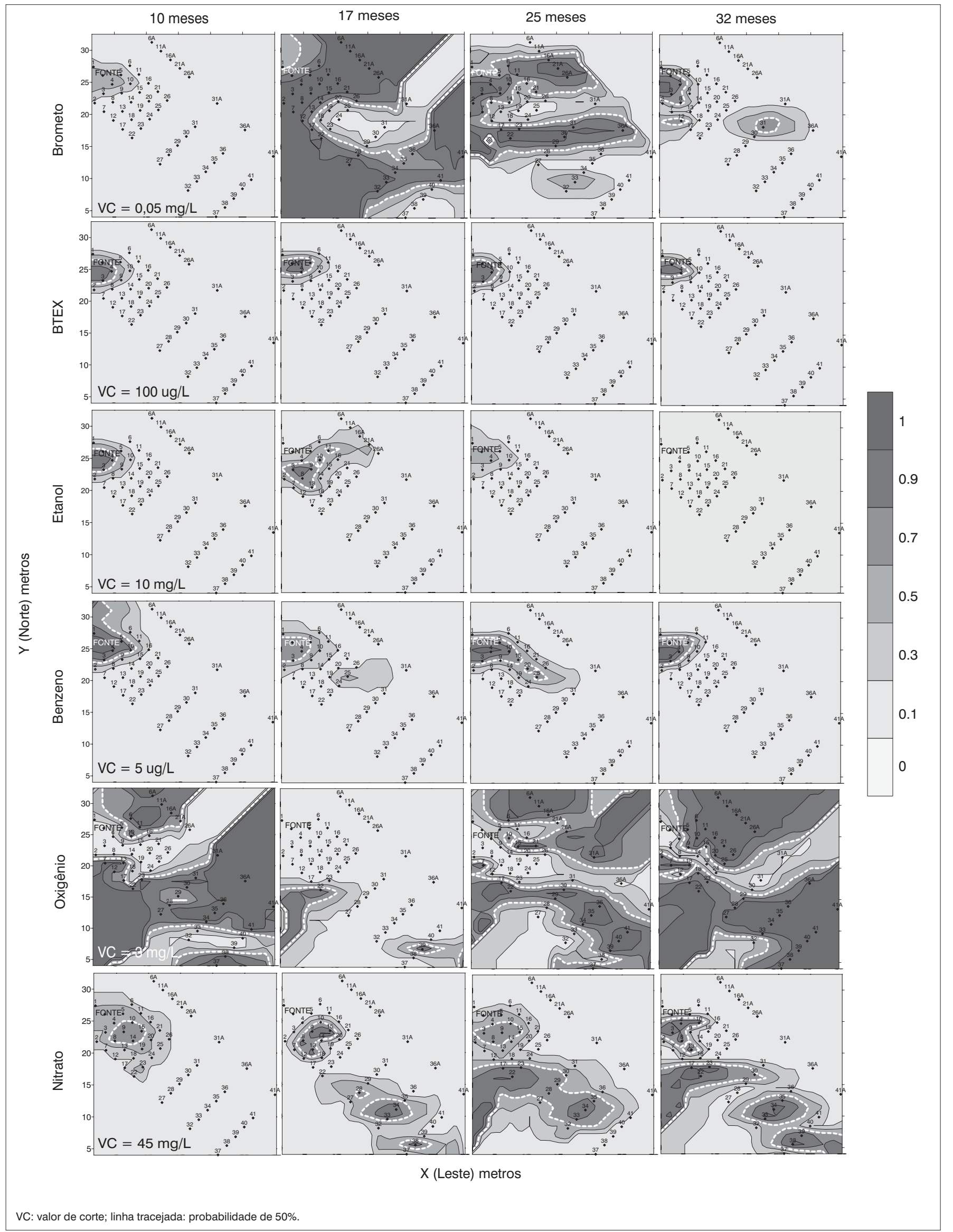

Figura 4 - Distribuição espacial de brometo, etanol, benzeno, nitrato e oxigênio dissolvido na profundidade de 2,3 m 


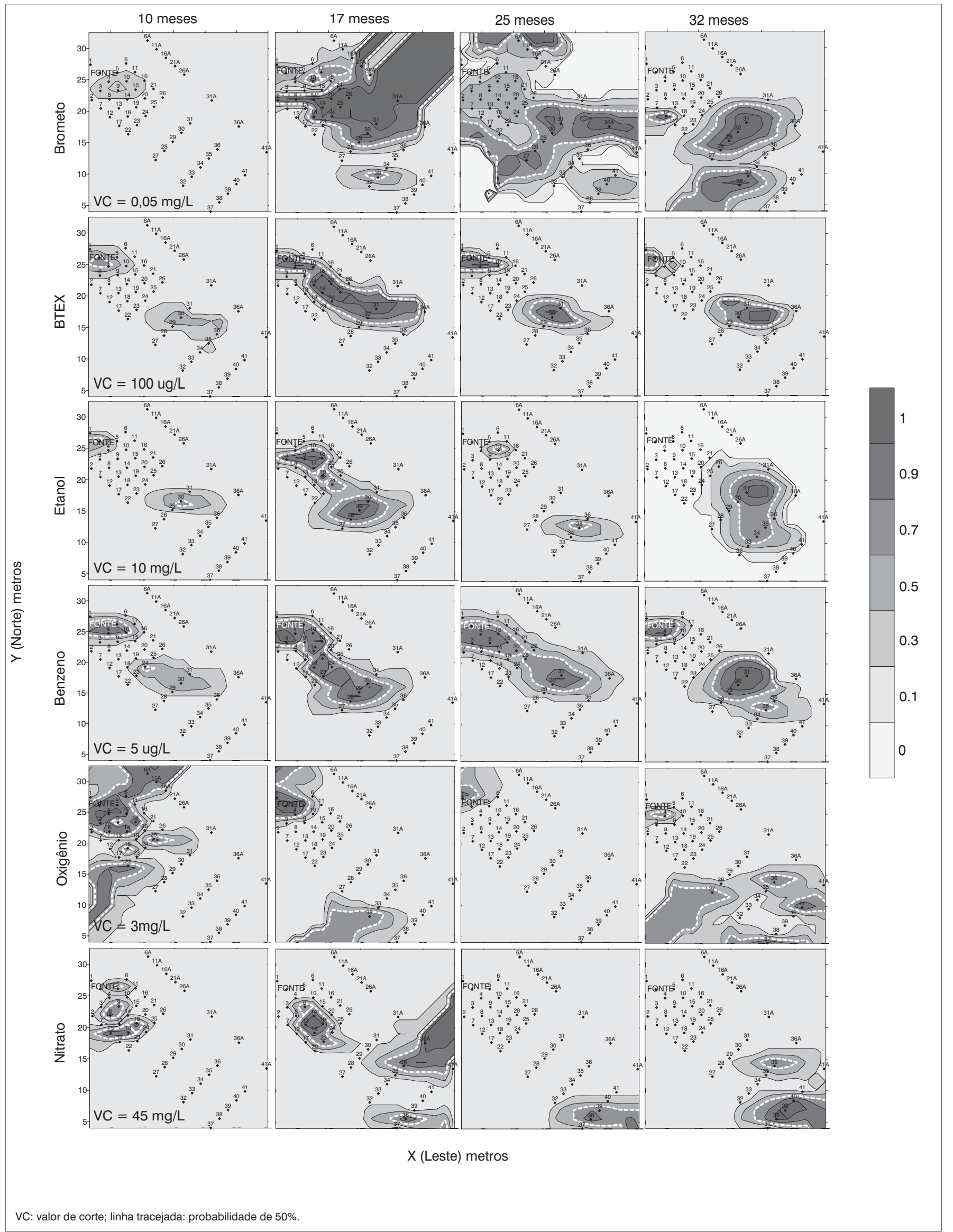

Figura 5 - Distribuição espacial de brometo, etanol, benzeno, nitrato e oxigênio dissolvido na profundidade de 5,8 m 


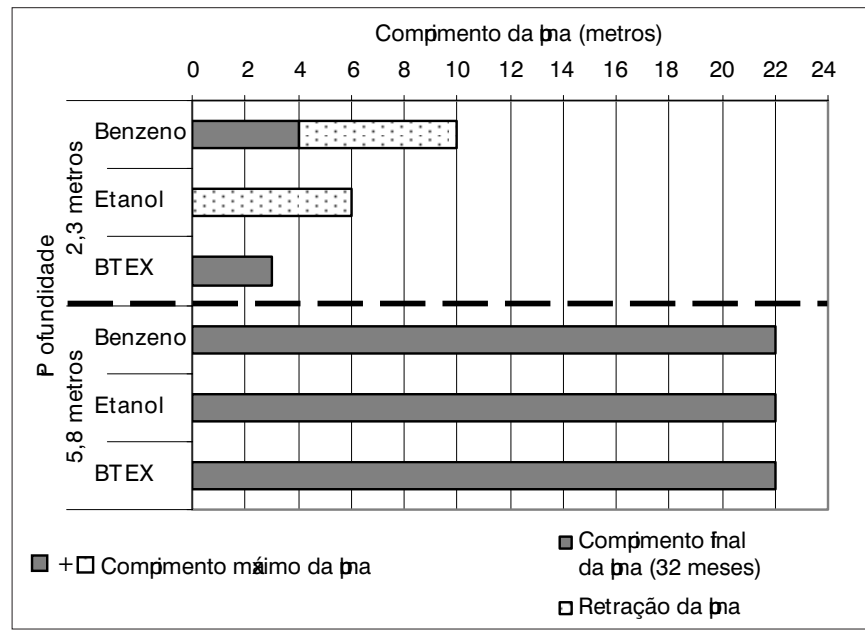

Figura 6 - Resumo do avanço e retração das plumas dos compostos BTEX e etanol com a profundidade até 32 meses após derramamento controlado de gasolina

fileiras de poços da área experimental indicou que a concentração mediana de nitrato foi sempre inferior aos padrões exigidos pela legislação. No entanto, cuidados devem ser tomados para que se tenha um monitoramento frequente e em poços multiníveis do avanço das plumas de BTEX, etanol e nitrato. O avanço da pluma de etanol nas regiões onde a quantidade de nitrato adicionado não foi suficiente demonstrou a possibilidade de separação das plumas de BTEX. Essa configuração de pluma implica dificuldades maiores para a definição da extensão da área atingida pela contaminação durante uma investigação.

\section{Agradecimentos}

Este trabalho foi financiado pela Petrobras e, através de bolsa de doutorado, pelo Conselho Nacional de Desenvolvimento Científico e Tecnológico (CNPq).

\section{Referências}

ALMEIDA, R. et al. Método geoestatístico para modelagem ambiental de poluentes em sistemas lacustres: Amazônia ocidental. In: XIII SIMPÓsIO BRASILEIRO DE SENSORIAMENTO REMOTO, Anais..., Florianópolis: p. 2247-2253, 2007.

ALVAREZ, P.J.J.; HUNT, C.S. The effect of fuel alcohol on monoaromatic hydrocarbon biodegradation and natural attenuation. Revista Latinoamericana de Microbiologia, v. 44, n. 2, p. 83-104, 2002.

AMERICAN PETROLEUM INSTITUTE. Groundwater remediation strategies tool. Regulatory Analysis and Scientific Affairs Department, n. 4730, EUA, Dec. 2003.

APHA/AWWA/WEF. Standard methods for the examination of water and wastewater. 18. ed. Washington, DC: APHA, 1992.

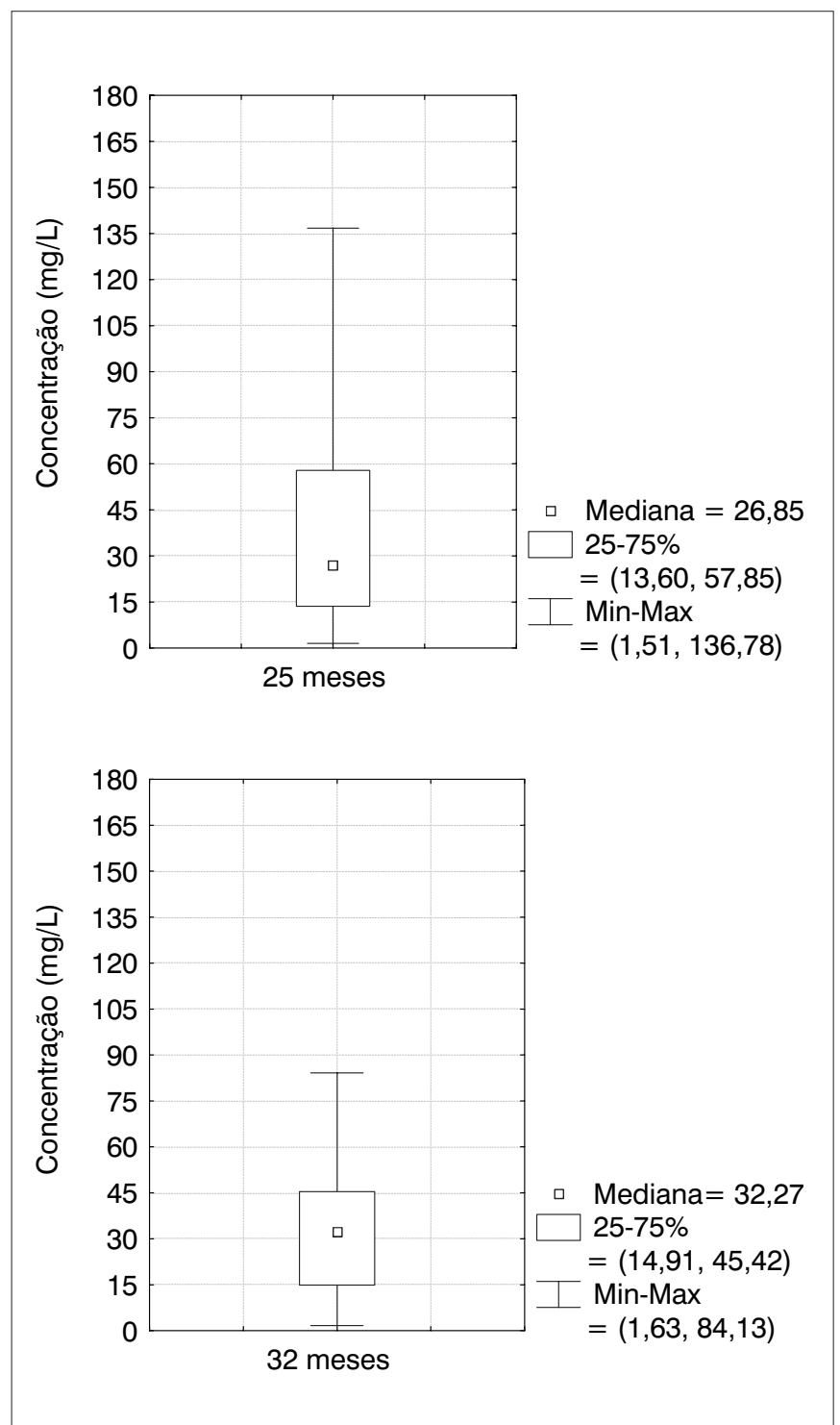

Figura 7 - Avaliação do transporte do nitrato à jusante da área experimental aos 25 e 32 meses de monitoramentos
CATTLE, J.A.; MCBRATNEY, A.B.; MINASNY, B. Kriging method evaluation for assessment the spatial distribution of urban soil lead contamination. Journal of Environment Quality, v. 31, p. 1576-1588, 2002.

CHEN, D.Y.; BARKER, J.F.; GUI, L. A strategy for aromatic bioremediation under anaerobic conditions and the impacts of ethanol: a microcosm study. Journal of Contaminant Hydrology, v. 96, p. 17-31, 2008.

CHIANG, C.Y. et al. Aerobic biodegradation of benzene, toluene, and xylene in a sandy aquifer: data analysis and computer modeling. Ground Water, v. 27, n. 6, p. 823-834, 1989.

CONSELHO NACIONAL DO MEIO AMBIENTE (Conama). Resolução 396, de 3 de abril de 2008. Disponível em: http://www.mma.gov.br/port/ conama/legiabre.cfm?codlegi=562. Acesso em: 6 de outubro de 2008. 
COOPER, R.M.; STOCK, J.D. Geostatistics applied to groundwater contamination II. Application. Journal of Environmental Engineering, v. 114, n. 2, p. 287-299, 1988.

CORSEUIL, H.X.; et al. Solução corretiva baseada no risco (SCBR): modelo matemático de tomada de decisão para o gerenciamento ambiental de águas subterrâneas contaminadas. In: XIV CONGRESSO BRASILEIRO DE ÁGUAS SUBTERRÂNEAS, 2006, Curitiba, Paraná, Anais... São Paulo: Abas, 2006

CORSEUIL, H.X.; HUNT, C.S.; SANTOS, R.C.F. The influence of gasoline oxygenate ethanol on aerobic and anaerobic BTEX biodegradation. Water Research, v. 32, n. 7, p. 2065-2072, 1998.

COSTA, A.H.R. Bioestimulação com injeção de nitrato em águas subterrâneas impactadas por derramamento de gasolina com etanol. 234 f. Tese (Doutorado em Engenharia Ambiental) - Departamento de Engenharia Sanitária e Ambiental, UFSC, 2008

CUNNINGHAM, J.A. et al Enhanced in situ bioremediation of BTEXcontaminated groundwater by combinated injection of nitrate and sulfate. Environmental Science and Technology, v. 35, p. 1663-1670, 2001.

DA SILVA, M.L.B.; RUIZ-AGUILAR, G.M.L.; ALVAREZ, P.J.J. Enhanced anaerobic biodegradation of BTEX: ethanol mixtures in aquifer columns amended with sulfate, chelated ferric iron or nitrate. Biodegradation, v. 16, p. 105-114, 2005.

EDMUND, W.M.; MILES, D.L.; COOK, J.M. A comparative study of sequencial redox processes in the three British Aquifers. In: ERIKSSON, E. (Ed.). Hydrochemical balance of freshwater systems. Washington, D.C: Internacional Association of Hydrogeological Sciences, 1984. v. 150, p. 55-70.

HUTCHINS, S.R. Biodegradation of monoaromatic hydrocarbons by aquifer microorganisms using oxygen, nitrate, or nitrous oxide as the terminal electron acceptor. Applied and Environmental Microbiology, v. 57, n. 8, p. 2403-2407, 1991
HUTCHINS, S.R.; MILLER, D.E.; THOMAS, A. Combined laboratory/ field study on the use of nitrate for in situ bioremediation of a fuelcontaminated aquifer. Environmental Science and Technology, v. 32, p. 1832-1840, 1998.

KWOK, C.; LOH, K. Effects of Singapore soil type on bioavailability of nutrients in soil bioremediation. Advances in Environment Research, v. 7, n. 4, p. 889-900, 2003.

LANDIM, P.M.B. Análise estatística de dados geológicos. São Paulo: Unesp, 2003.

LANDIM, P.M.B.; USHIZIMA, T.M. GEOEAS: exemplo de aplicação em análise geoestatística. DGA/IGCE/UNESP/Rio Claro. Laboratório de Geoinformática, Texto Didático 11, 2003, disponível em < http://www. rc.unesp.br/igce/geologia/GAA01001/aulas_files/TextoGeoeas.PDF> Acesso em: 23 de maio de 2003.

NUNES, C.C. ; CORSEUIL, H.X. Importância do Etanol na Atenuação do Etanol na Atenuação Natural de Águas Subterrâneas impactadas por gasolina. Revista Engenharia Sanitária e Ambiental, v. 12, n. 3, p. 259265, jul./set. 2007.

RITTMANN, B.E.; MCCARTY, P.L. Stoichiometry and bacterial energetics. Environmental Biotechnology, New York, McGraw-Hill, p. 126-161, 2001.

SCHREIBER, M.E.; BAHR, J.M. Nitrate-enhanced bioremediation of BTEX-contaminated groundwater: parameter estimation from naturalgradient tracer experiments. Journal of Contaminant Hydrology, v. 55, p. 29-56, 2002.

WIEDEMEIER, T.H. et al Natural attenuation of fuels and chlorinated solvents in the subsurface. New York: John Wiley \& Sons Inc., 1999.

WILSON, L.P.; D'ADAMO, P.C.; BOUWER, E.J. Biodegradation of aromatic compounds under mixed oxygen/denitrifying condition: a review. Journal of Industrial Microbiology \& Biotechnology, v. 18, p. 116-130, 1997. 